\title{
Ivan ILLICH, Celebrare la consapevolezza. Opere complete. Volume I
}

Préface de Giorgio Agamben, Vicenza, Neri Pozza Editore, coll. « La quarta prosa », 2020, $894 \mathrm{p}$.

\section{Étienne Fouilloux}

\section{(2) OpenEdition \\ 12 Journals}

\section{Édition électronique}

URL : http://journals.openedition.org/assr/57752

DOI : $10.4000 /$ assr. 57752

ISSN : $1777-5825$

Éditeur

Éditions de l'EHESS

\section{Édition imprimée}

Date de publication : 31 décembre 2020

Pagination : 230-231

ISBN : 978-2-7132-2826-1

ISSN : 0335-5985

Référence électronique

Étienne Fouilloux, «Ivan ıьıсн, Celebrare la consapevolezza. Opere complete. Volume I », Archives de sciences sociales des religions [En ligne], 192 | octobre-décembre 2020, mis en ligne le 31 décembre 2020, consulté le 25 janvier 2021. URL : http://journals.openedition.org/assr/57752 ; DOI : https:// doi.org/10.4000/assr.57752

Ce document a été généré automatiquement le 25 janvier 2021.

(c) Archives de sciences sociales des religions 


\section{Ivan ILLICH, Celebrare la consapevolezza. Opere complete. Volume I}

Préface de Giorgio Agamben, Vicenza, Neri Pozza Editore, coll. « La quarta prosa », 2020, $894 \mathrm{p}$.

\section{Étienne Fouilloux}

\section{RÉFÉRENCE}

Ivan ILLICH, Celebrare la consapevolezza. Opere complete. Volume I, édité par Fabio Milana, préface de Giorgio Agamben, Vicenza, Neri Pozza Editore, coll. « La quarta prosa », 2020, $894 \mathrm{p}$.

1 Contempteur des religions de la modernité, ces nouvelles "vaches sacrées » que sont pour lui l'école ou la médecine, et apôtre d'une révolution culturelle non violente, Ivan Illich a été l'un des maîtres à penser de la génération contestataire des années 1970. Aussi curieux que cela puisse paraitre, son œuvre abondante et profuse n'avait jamais été rassemblée. Cette lacune est heureusement réparée, en italien, par Fabio Milana, l'un des meilleurs connaisseurs de la figure d'Illich et de son œuvre. Il y traduit, présente et annote, dans ce premier volume, les livres et articles produits par celui-ci, les premiers sous pseudonyme, entre 1955 et 1971. Bon nombre d'entre eux, qui ont connu plusieurs versions avant d'être publiés, sont difficiles à dater. La présente édition ne suit donc pas un ordre chronologique. Fabio Milana reprend d'abord les quatre recueils de 1970-1971 et 1985 dans lesquels Illich a rassemblé l'essentiel de sa production antérieure: The Church, Change and Development, Celebration of Awareness. A Call for Institutional Revolution, Ensayos sobre la transcendencia et The Powerless Church and Other Selected Writings, 1955-1985 (plus un essai sur la Bolivie en révolution). Il y ajoute, dans une sixième partie, les textes dispersés qui n'ont pas été repris dans ces recueils 
et, dans une septième partie, la thèse inédite de 1951 sur Les fondements philosophiques de l'historiographie dans Arnold Joseph Toynbee.

La chronologie retrouve ses droits dans la bibliographie et surtout dans une longue et dense introduction qui éclaire le parcours singulier d'Illich depuis sa formation cléricale jusqu'au moment où il décide, à la charnière des années 1960 et 1970, de ne plus être un prêtre catholique, mais un « auteur de livres ». Né en 1926 dans une famille de commerçants et d'industriels, Ivan Illich est le fils d'un croate catholique italophone et d'une mère juive germanophone convertie au christianisme, protestant puis catholique. Réfugié avec sa mère à Florence pour fuir la persécution nazie, il entre en 1945 au collège Capranica qui forme le personnel diplomatique du Saint-Siège et prend ses grades à l'Université grégorienne jusqu'à la licence de théologie obtenue en 1951, année de son ordination sacerdotale et de la soutenance de sa thèse sur Toynbee préparée sous la direction du bénédictin Albert Auer à l'Université de Salzbourg. Plutôt que faire carrière dans la diplomatie vaticane, il choisit cette même année de devenir vicaire dans la paroisse du nord de Manhattan qui subit de plein fouet l'immigration portoricaine. Il se dépense sans compter pour l'accueil des immigrants tout en contestant une américanisation qui les dépouille de leur identité. Remarqué pour son efficacité, il est nommé en 1956 vice-recteur de l'université catholique de la République dominicaine et doté d'une prélature. En 1960 toutefois, il se brouille avec la hiérarchie locale en refusant de faire voter pour le parti démocrate-chrétien aux élections qui voient le succès de John Kennedy. Il fonde alors avec quelques amis, à Cuernavaca au Mexique, le Centre interculturel de formation ou Cif qui initie à l'Amérique hispanophone les missionnaires américains et européens chargés de pallier le manque de vocations locales, tout en contestant l'idéologie du développement dont ils sont porteurs. Aussi fonde-t-il, à l'intérieur du Cif, en 1966, le Centre interculturel de documentation (Cidoc) sur l'Amérique latine afin d'imaginer un autre projet pour le continent. De la critique de la mission à la critique du rôle du clergé au sein de l'Église catholique il n'y a qu'un pas, franchi en 1967 dans un article, "The Vanishing Clergyman", qui vaut à Mgr Illich une enquête de la part de la Congrégation pour la doctrine de la foi. Refusant le secret de la procédure, il la rend publique avant de renoncer à la prêtrise en 1969. Déjà bien engagé dans la dénonciation du rôle de la scolarisation, il tire en 1971 le bilan de quinze ans d'engagements jalonnés de textes qui en expliquent les principaux choix.

3 Avec une grande maîtrise de l'histoire politique, intellectuelle et religieuse d'une époque particulièrement riche en soubresauts de tous types, Fabio Milana restitue cet itinéraire peu commun à son contexte, celui de l'utopie du développement pour l'Amérique latine et de l'aggiornamento pour l'Église catholique, de l'Alliance pour le progrès et du concile Vatican II, mais aussi des velléités révolutionnaires et de l'accélération de la sécularisation. Entre Karl Marx, Max Weber et Karl Barth, Ivan Illich trace une voie originale dont les textes ici rassemblés fournissent les principaux aiguillages. On souhaite que l'entreprise de publication des œuvres complètes du métis culturel de génie que fut Illich se poursuive rapidement, et surtout que Fabio Milana ne tarde pas à nous donner la biographie annoncée de son héros. 